\title{
Remission of diffuse ulcerative duodenitis in a patient with ulcerative colitis after infliximab therapy: a case study and review of the literature
}

\author{
Yong-Sung Choi ${ }^{1}$, Jong Kyu Kim ${ }^{1}$, Wan Jung Kim ${ }^{1}$, Mi-Jung Kim² \\ Departments of ${ }^{l}$ Gastroenterology and ${ }^{2}$ Pathology, Daehang Hospital, Seoul, Korea
}

Although ulcerative colitis (UC) is confined to colonic and rectal mucosa in a continuous fashion, recent studies have also demonstrated the involvement of upper gastrointestinal tract as diagnostic endoscopy becomes more available and technically advanced. The pathogenesis of UC is not well established yet. It might be associated with an inappropriate response of host mucosal immune system to gut microflora. Although continuous and symmetric distribution of mucosal inflammation from rectum to colon is a typical pattern of UC, clinical feature and course of atypically distributed lesions in UC might also help us understand the pathogenesis of UC. Herein, we report a case of duodenal involvement of UC which successfully remitted after infliximab therapy. Endoscopic and pathologic findings before and after administration of anti-tumor necrosis factor suggest that the pathogenesis of upper gastrointestinal involvement of UC may be similar to that of colon involvement. (Intest Res 2019;17:273-277)

Key Words: Duodenitis; Colitis, ulcerative; Remission

\section{INTRODUCTION}

Ulcerative colitis (UC) is characterized by chronic mucosal inflammation and confined to rectum and colon unlike CD which can involve whole GI tract from esophagus to anus. Recently, some studies have demonstrated the involvement of upper GI tract in patients with UC as diagnostic endoscopy becomes more available and technically advanced. However, its clinical course and the association with colonic lesion are still unknown because it is very rare. Here, we report a patient with acute exacerbated UC and symptomatic diffuse duodenitis which was successfully treated with infliximab.

Received September 6, 2018. Revised November 6, 2018.

Accepted November 7, 2018.

Correspondence to Yong-Sung Choi, Department of Gastroenterology,

Daehang Hospital, 2151 Nambusunhwan-ro, Seocho-gu, Seoul 06699, Korea.

Tel: +82-2-63888-114, Fax: +82-2-63888-115, E-mail: yschoi427@naver.

com

ORCID Yong-Sung Choi (https://orcid.org/0000-0003-0453-2322)

\section{CASE REPORT}

A 45-year-old male who had a family history of UC visited Daehang Hospital presenting with abdominal pain and frequent (>10/day) bloody diarrhea. He was diagnosed with left-sided UC about 10 years ago. He maintained remission with combination mesalamine therapy. The patient was admitted to our hospital and intravenous corticosteroid (hydrocortisone 300 $\mathrm{mg}$ /day) was started. On admission, his body temperature was $38.8^{\circ} \mathrm{C}$. Blood test revealed elevation of $\mathrm{CRP}$, leukocytosis and mild anemia as follows; CRP $4.0 \mathrm{mg} / \mathrm{dL}$, white blood cells $12,900 / \mu \mathrm{L}$, and hemoglobin $10.4 \mathrm{~g} / \mathrm{dL}$. Colonoscopy showed diffuse and ulcerative inflammation with spontaneous mucosal hemorrhage and profuse mucopurulent exudates from the rectum to descending colon in a continuous and symmetric fashion (Fig. 1A).

For a week, bloody diarrhea persisted despite intravenous infusion of corticosteroid. The patient also complained of se- 

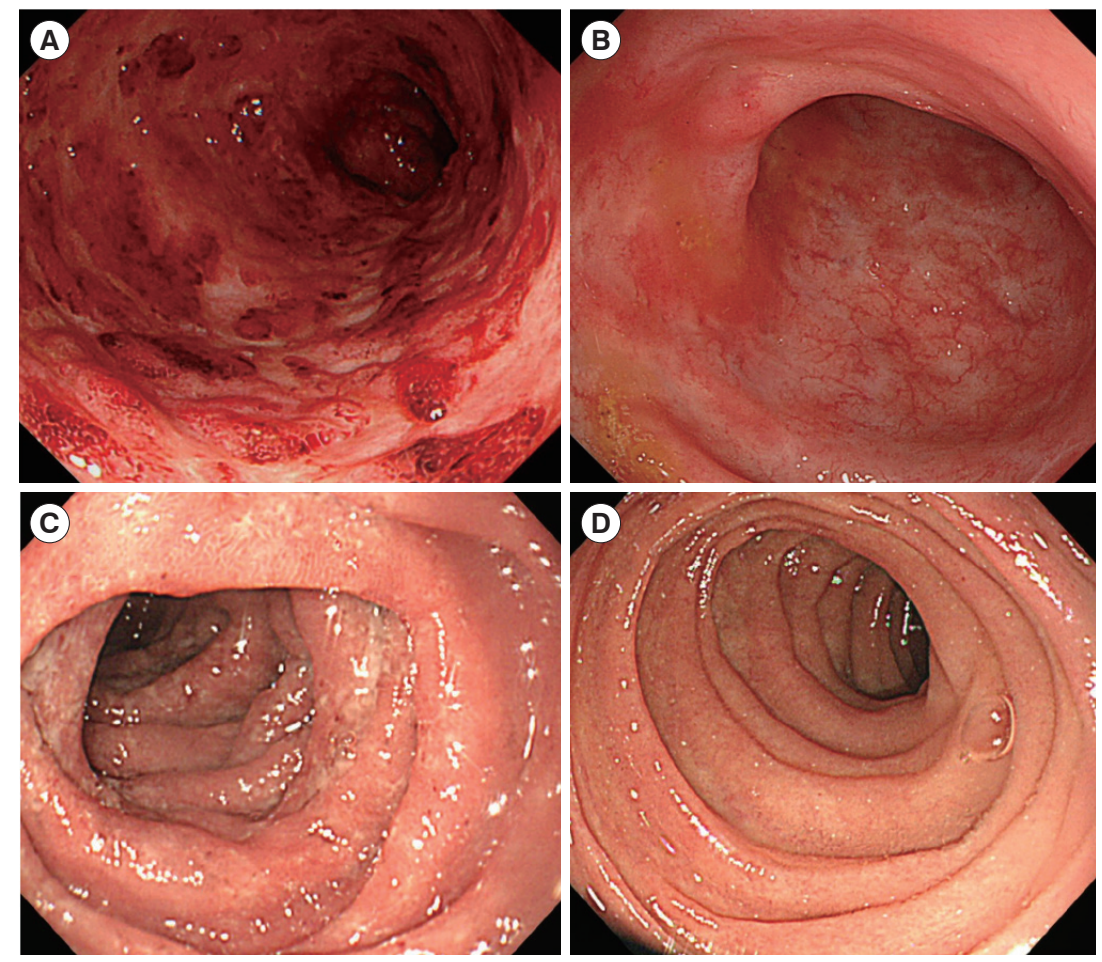

Fig. 1. Endoscopic findings. (A) At initial colonoscopy, diffuse ulcerative inflammation with profuse exudation and spontaneous mucosal hemorrhage. (B) At 3 months follow-up colonoscopy after induction therapy with infliximab, mucosal healing showing whitish scar formation was noted. (C) At initial esophagogastroduodenoscopy (EGD), diffuse edematous and ulcerative inflammation on the bulb and 2nd portion of duodenum. (D) At 3 months follow-up EGD after infliximab induction therapy, endoscopic mucosal healing was achieved on the duodenal mucosa showing scar change.
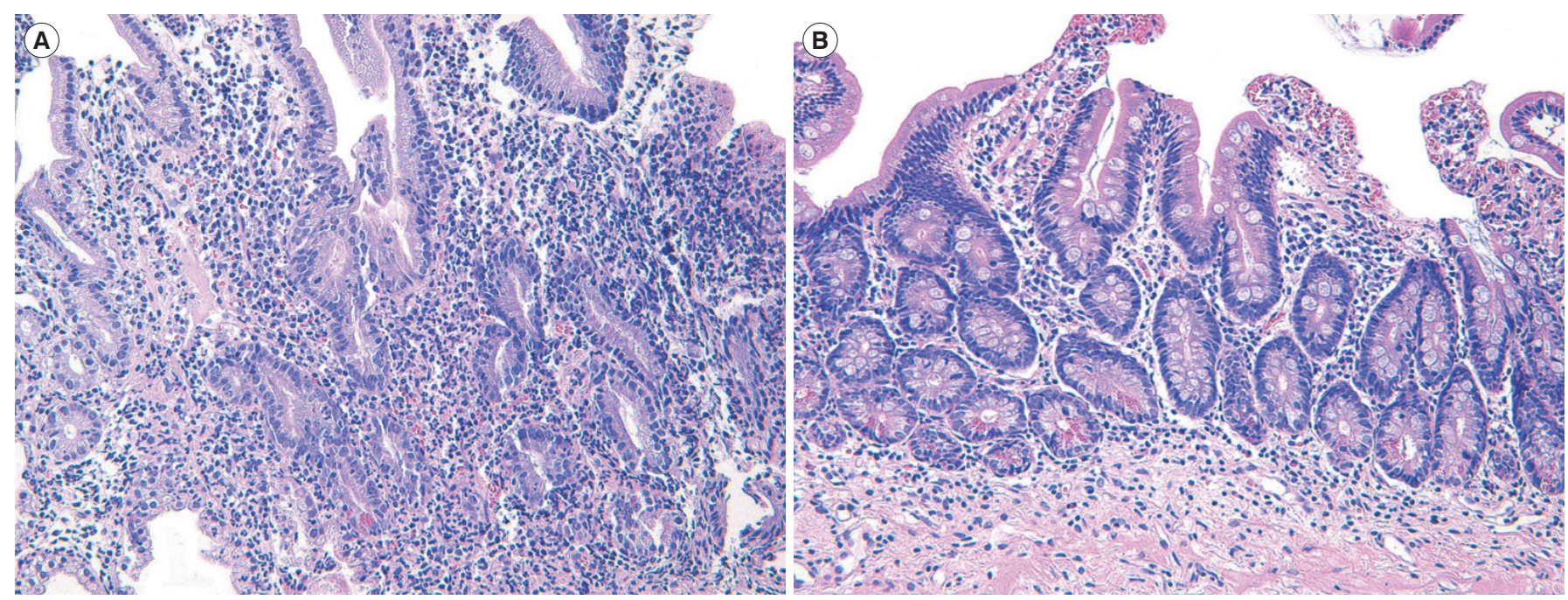

Fig. 2. Histopathological findings. (A) High-power magnification of duodenum showing histologic features of chronic active duodenitis. There is a manifestation of chronic active colitis with crypt distortion, basal lymphoplasmacytosis and crypt abscess (H\&E stain, $\times 200)$. (B) High-power magnification of duodenum after infliximab treatment. Note the decreased density of inflammatory cell infiltrates in lamina propria as well as decreased active inflammation compared to those of prior medical treatment. Instead of prominent inflammatory cell infiltrates, subepithelial fibrosis is also noted (H\&E stain, $\times 200)$.

vere epigastric pain and vomiting. We added proton pump inhibitor, but his symptoms did not improve. Simple abdominal radiography was performed and it showed no sign of intestinal obstruction or toxin megacolon. We highly recommended esophagogastroduodenoscopy (EGD) which showed diffuse edematous and ulcerative inflammation on the bulb and 2nd portion of duodenum (Fig. 1C). On histopathologic examination, marked inflammatory cell infiltration and cryptitis were noted without evidence of granuloma or inclusion body (intranuclear or intracytoplasmic) (Fig. 2A). Helicobacter pylori 


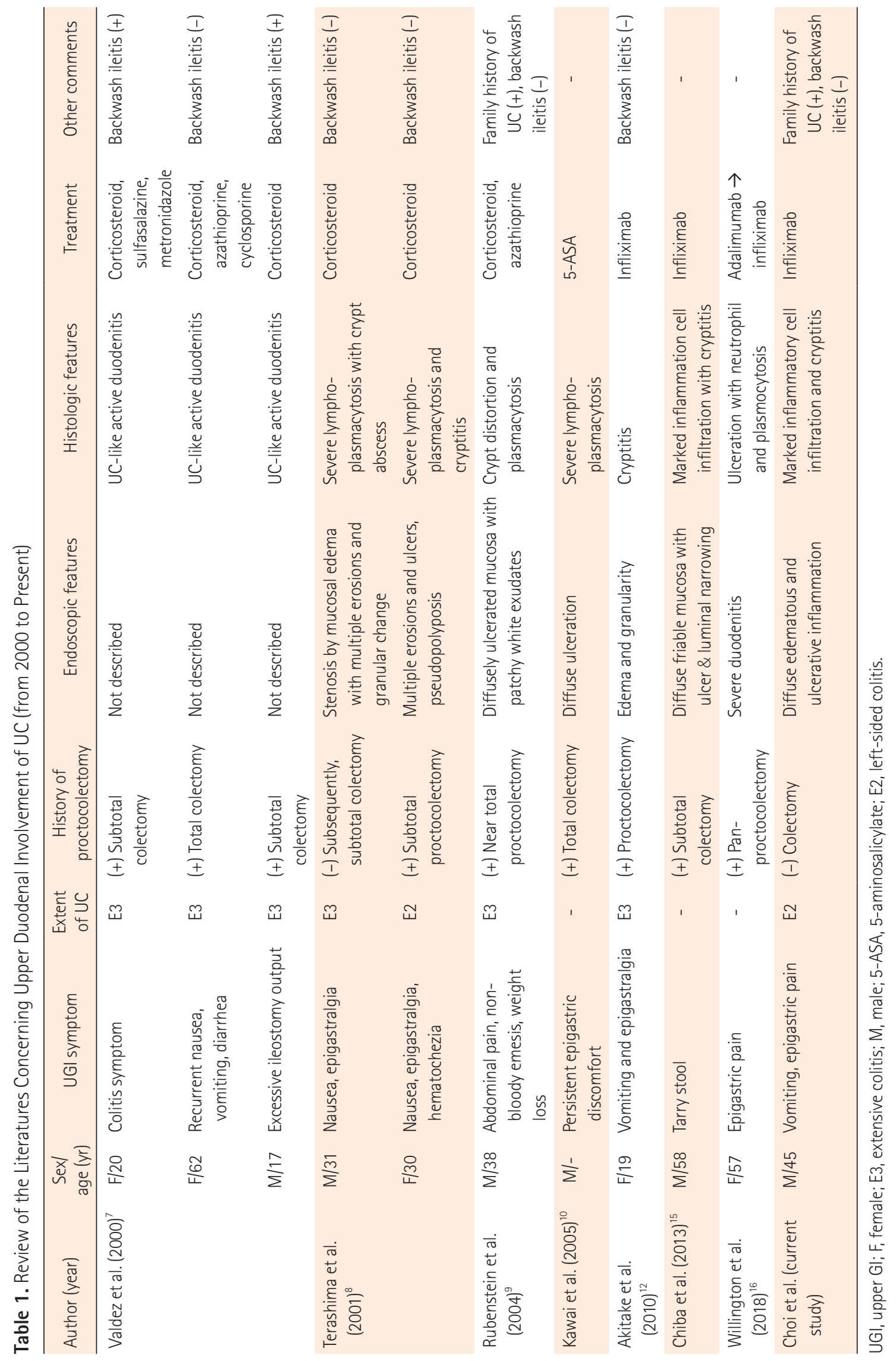


was not detected. We started standard induction therapy of infliximab (300 mg infusion at 0, 2nd, and 6th weeks). His epigastric symptom and bloody diarrhea improved abruptly. Three months later, follow-up colonoscopy and EGD showed mucosal healing with whitish scarring (Fig. 1B and D). On histopathologic examination of duodenal mucosa, there was decreased density of inflammatory cell infiltrates in lamina propria with decreased active inflammation compared to those at prior medical treatment. Instead of prominent inflammatory cell infiltrates, subepithelial fibrosis was noted (Fig. 2B). After more than 1 year, the patient is still sustaining clinical remission with infliximab maintenance therapy.

\section{DISCUSSION}

UC is an idiopathic IBD characterized by mucosal inflammation in a continuous fashion from rectum to colon. However, recent studies have reported that colonic skip lesions such as patchy or segmental inflammation can be found in patients with UC as well as $\mathrm{CD}^{1,2}$ Another exception of conventional definition of UC can also be encountered in practice. Some case reports have demonstrated gastroduodenal or enteric involvement of UC along with advancement of endoscopic imaging techniques. ${ }^{3-6}$ Thompson and Bargen ${ }^{6}$ firstly reported 2 cases of ulcerative duodenitis in patients with UC in 1960. Since then, some case reports or cases series have been published (Table 1) ${ }^{7-16}$ In 1990s, Ruuska et al. ${ }^{3}$ prospectively evaluated upper GI involvement of 47 pediatric UC patients (esophageal ulcer in 2, gastritis in 22, duodenitis or duodenal ulcer in 18) and designated them simply as "nonspecific inflammation." Japanese reports suggested that the prevalence of gastroduodenal involvement of UC was $4.7 \%$ to $7.6 \%$. Such involvement of UC was only found in cases with pancolitis or in cases with proctocolectomy. ${ }^{11,13}$

Symptoms of gastroduodenal involvement may vary, including epigastric pain, nausea and vomiting. Asymptomatic or screening cases are more common, accounting for $60 \%$ to $75 \%$ of cases. ${ }^{11,13}$ In our case, the patient had severe epigastric pain, which was different from the usual pattern or location of UC. The symptom did not improve despite intravenous injection of proton pump inhibitor. After induction therapy with infliximab, his epigastric symptom improved abruptly before clinical improvement of UC symptoms such as diarrhea and hematochezia. Histopathologic characteristics of duodenitis of UC is similar to UC, showing neutrophilic cryptitis, crypt abscess and basal lymphoplasmacytosis without pathognomonic finding.
Therefore, other chronic conditions such as Helicobacter-related gastroduodenitis, CD, lymphoma and opportunistic viral infections need to be ruled out for differential diagnosis.

Standard therapy for gastroduodenitis of UC has not been established yet. However, for a symptomatic case, 5-aminosalicylate, corticosteroid and anti-TNF can be used, similar to treatment for colitis of UC. In literature review, 3 cases of diffuse duodenitis of UC have been successfully treated with anti-TNF (Table 1). ${ }^{12,15,16}$ All of them were proctocolectomized cases, so only gastroduodenal mucosa was evaluated by EGD. However, in our case, we could compare endoscopic and microscopic findings of both colon and duodenal inflammation before and after infliximab therapy (Figs. 1 and 2). Follow-up EGD and colonoscopy demonstrated simultaneous endoscopic and pathologic remission of both duodenal and colonic mucosal inflammation as well as clinical remission. This might be associated with common pathogenic process in upper GI inflammation of UC, although the pathophysiology of UC is not well-known yet. In the case of upper gastroduodenal involvement of UC without symptom, it is currently unclear whether it might be related to poor prognosis like CD or it may require medical therapy targeting upper GI inflammation. Given the fact that most cases with upper GI involvement of UC had pancolitis or underwent proctocolectomy, it might be associated with extensive or severe behavior of UC. Similarly, the clinical significance of periappendiceal orifice inflammation or right-sided skip inflammation of UC is controversial. ${ }^{1,2,17,18}$ Long-term clinical course of UC with upper GI tract as well as colonic skip inflammation should be evaluated to elucidate the pathophysiology of UC.

In conclusion, here we report a patient with acute exacerbated UC and symptomatic diffuse duodenitis successfully treated with infliximab. This case demonstrates that endoscopic and pathologic remission of mucosal inflammation of upper GI tract and colonic lesion of UC can be achieved by infliximab. This suggests that the pathogenesis of upper GI involvement of UC may be similar to that of colon involvement. We believe that this case can help us understand various behaviors of UC and predict its clinical course.

\section{FINANCIAL SUPPORT}

The authors received no financial support for the research, authorship, and/or publication of this article. 


\section{CONFLICT OF INTEREST}

No potential conflict of interest relevant to this article was reported.

\section{AUTHOR CONTRIBUTION}

Conceptualization and writing original draft: Choi YS. Writingreview and editing: Kim WJ, Kim JK, Kim MJ. Approval of final manuscript: all authors.

\section{REFERENCES}

1. Mutinga ML, Odze RD, Wang HH, Hornick JL, Farraye FA. The clinical significance of right-sided colonic inflammation in patients with left-sided chronic ulcerative colitis. Inflamm Bowel Dis 2004;10:215-219.

2. Choi YS, Kim WJ, Kim JK, Kim DS, Lee DH. Efficacy of topical 5-aminosalicylate monotherapy in patients with ulcerative proctitis with skip inflammation. J Gastroenterol Hepatol 2018; 33:1200-1206.

3. Ruuska T, Vaajalahti P, Arajärvi P, Mäki M. Prospective evaluation of upper gastrointestinal mucosal lesions in children with ulcerative colitis and Crohn's disease. J Pediatr Gastroenterol Nutr 1994;19:181-186.

4. Kaufman SS, Vanderhoof JA, Young R, Perry D, Raynor SC, Mack DR. Gastroenteric inflammation in children with ulcerative colitis. Am J Gastroenterol 1997;92:1209-1212.

5. Mitomi H, Atari E, Uesugi H, et al. Distinctive diffuse duodenitis associated with ulcerative colitis. Dig Dis Sci 1997;42:684693.

6. Thompson JW 3rd, Bargen JA. Ulcerative duodenitis and chronic ulcerative colitis: report of two cases. Gastroenterology 1960; 38:452-455.

7. Valdez R, Appelman HD, Bronner MP, Greenson JK. Diffuse duodenitis associated with ulcerative colitis. Am J Surg Pathol 2000;24:1407-1413.
8. Terashima S, Hoshino Y, Kanzaki N, Kogure M, Gotoh M. Ulcerative duodenitis accompanying ulcerative colitis. J Clin Gastroenterol 2001;32:172-175.

9. Rubenstein J, Sherif A, Appelman H, Chey WD. Ulcerative colitis associated enteritis: is ulcerative colitis always confined to the colon? J Clin Gastroenterol 2004;38:46-51.

10. Kawai K, Watanabe T, Nakayama H, Roberts-Thomson I, Nagawa H. Images of interest. Gastrointestinal: small bowel inflammation and ulcerative colitis. J Gastroenterol Hepatol 2005;20: 1791.

11. Hori K, Ikeuchi H, Nakano H, et al. Gastroduodenitis associated with ulcerative colitis. J Gastroenterol 2008;43:193-201.

12. Akitake R, Nakase H, Tamaoki M, Ueno S, Mikami S, Chiba T. Modulation of Th1/Th2 balance by infliximab rescues postoperative occurrence of small-intestinal inflammation associated with ulcerative colitis. Dig Dis Sci 2010;55:1781-1784.

13. Hisabe T, Matsui T, Miyaoka M, et al. Diagnosis and clinical course of ulcerative gastroduodenal lesion associated with ulcerative colitis: possible relationship with pouchitis. Dig Endosc 2010;22:268-274.

14. Lin J, McKenna BJ, Appelman HD. Morphologic findings in upper gastrointestinal biopsies of patients with ulcerative colitis: a controlled study. Am J Surg Pathol 2010;34:1672-1677.

15. Chiba M, Ono I, Wakamatsu H, Wada I, Suzuki K. Diffuse gastroduodenitis associated with ulcerative colitis: treatment by infliximab. Dig Endosc 2013;25:622-625.

16. Willington AJ, Taylor G, White J, Gearry RB. Gastrointestinal: ulcerative colitis-associated duodenitis. J Gastroenterol Hepatol 2018;33:973.

17. Byeon JS, Yang SK, Myung SJ, et al. Clinical course of distal ulcerative colitis in relation to appendiceal orifice inflammation status. Inflamm Bowel Dis 2005;11:366-371.

18. Naves JE, Lorenzo-Zúñiga V, Marín L, et al. Long-term outcome of patients with distal ulcerative colitis and inflammation of the appendiceal orifice. J Gastrointestin Liver Dis 2011;20:355358. 